\title{
PENGUKURAN KUALITAS WEBSITE ELEVENIA MENGGUNAKANN WEBQUAL 4.0 DAN IMPORTANCE PERFORMANCE ANNALYSIS
}

\author{
Johanes Fernandes Andry ${ }^{1}$, Gary Juliawan ${ }^{2}$, Hosea ${ }^{3}$, Johan Wijaya ${ }^{4}$ \\ ${ }^{1}$ Fakultas Teknologi dan Desain, Universitas Bunda Mulia \\ Jl. Lodan Raya No. 2 Ancol, Jakarta Utara, Indonesia, 14430
}

${ }^{1}$ jandry@bundamulia.ac.id, ${ }^{2}$ garyjuliawan@gmail.com, ${ }^{3}$ hosea110897@gmail.com, ${ }^{4}$ wijayajohan215@gmail

\begin{abstract}
Abstrak- Elevenia merupakan E-Commerce Customer-to-Customer di Indonesia, didirikan tanggal 1-Maret-2014, dengan kondisinya yang terbilang baru dibanding beberapa kompetitornya, Elevenia harus memiliki kualitas website yang sesuai dengan keinginan penggunanya agar dapat menarik pelanggan maupun mempertahankan pelanggan lamanya. Pada penelitian ini penulis mengukur kualitas website Elevenia menurut pandangan pengguna, menggunakan metode WebQual4.0 dan Importance Performance Analysis, penelitian ini memperlihatkan atribut yang menurut pengguna harus lebih diperhatikan agar memenuhi kebutuhan atau ekspektasi dari kepentingan pengguna. Penggunaan diagram Cartesian berfungsi untuk melakukan Importance Performance Analysis yang berperan penting sebagai tolak ukur kualitas tersebut. Penelitian ini menghasilkan analisa, bahwa website Elevenia sudah memberikan rasa aman dan nyaman saat pengguna melakukan dan menyelesaikan transaksi, namun ada beberapa aspek yang harus diperbaiki dan diperhatikan, seperti mayoritas pengguna merasa bahwa tampilan dari website Elevenia kurang atraktif, dan pengalaman berbelanja mereka yang sedikit tidak begitu baik. Hasil ini dapat digunakan Elevenia sebagai feedback untuk memperbaiki kualitas website Elevenia dimasa mendatang.
\end{abstract}

Keywords-E-Commerce, WebQual4.0, Importance-Performance Analysis, Pengukuran Kualitas.

\section{PENDAHULUAN}

E-Commerce adalah kegiatan melakukan transaksi seperti membeli, menjual, menjual produk atau layanan, dan menggunakan teknologi yang ada. Teknologi yang digunakan oleh setiap e-commerce harus memiliki standar budaya dan juga sebuah proses bisnis [1]. E-commerce mengubah bisnis yang tradisional menjadi model bisnis ke bisnis (B2B) dan bisnis ke konsumen (B2C) yang beroperasi 7 hari seminggu dan 24 jam sehari [2], oleh karena itu, setiap e-commerce harus memelihara situs webnya karena hal tersebut adalah proses yang penting untuk bisnis mereka [3]. Jika situs web tidak dapat diakses, pelanggan akan atau dapat segera pindah ke $E$ Commerce lain. E-commerce memiliki dampak besar pada sektor layanan dan layanan transaksi online [4].

Seiring dengan berkembangnya perkembangan teknologi website, kualitas website selalu ikut berkembang dengan bertambahnya komponenkomponen yang digunakan pada website, karena itu dalam pengembangan aplikasi website, kualitas web menjadi bagian yang penting dalam rekayasa sebuah website [5]. Dengan kualitas website yang buruk dan lambat, maka pengunjung tidak akan kembali ke website yang sama, akan tetapi jika kualitas website bagus dan cepat, maka pengunjung akan kembali ke website tersebut [6], sehingga kualitas website memiliki pengaruh terhadap pengunjung yang datang ke situs tersebut. Pada situs e-commerce yang memiliki kualitas yang baik, maka secara langsung akan mempengaruhi keberhasilan $e$-commerce tersebut [7]. Kualitas website dibagi menjadi 3 bagian yaitu: kualitas sistem, kualitas informasi dan kualitas layanan [8]. Ketiga dimensi tersebut berpengaruh terhadap kepuasan user yang mengunjungi situs tersebut.

Ada beberapa teori yang berkembang, bahwa retensi pelanggan atau kesetiaan lebih berharga daripada mencoba mencari lebih banyak pelanggan [9]. Sebuah perusahaan, terutama perusahaan di bidang $E$ Commerce harus dapat membuat pelanggan mereka puas, tetapi mengetahui kepuasan pelanggan saja tidak memberi informasi kepada perusahaan secara detail, apa yang sebenarnya dapat membuat para pelanggan ini menjadi setia kepada perusahaan dalam jangka panjang [10]. Ada hal-hal yang sangat berpengaruh dalam suatu perusahaan, khususnya di bidang Teknologi Internet dan E-Commerce, yaitu kualitas layanan yang diberikan, kualitas layanan tersebut dapat memberikan dua hal yang vital dan dibutuhkan oleh perusahaan, Pertama, kualitas layanan dianggap sebagai keunggulan kompetitif yang harus dimiliki dan merupakan cara untuk menarik pelanggan baru; Kedua, kualitas layanan yang baik adalah hal yang penting untuk retensi pelanggan, dan meningkatkan loyalitas pelanggan [11]. Faktanya adalah bahwa akan jauh lebih mahal bagi perusahaan untuk menemukan pelanggan baru, daripada membuat pelanggan yang ada puas dan senang dengan apa yang perusahaan tawarkan [12]. Sehingga kualitas situs web ECommerce itu sendiri harus ditingkatkan, pelanggan menginginkan pengalaman dalam belanja online menjadi lebih mudah, dan merasa aman ketika menggunakan situs web.

Metode yang digunakan untuk menentukan kualitas situs web adalah WebQual 4.0. Stuart Barnes 
mengembangkan metode yang disebut WebQual 4.0 yang merupakan metode yang banyak digunakan untuk mengukur kualitas situs web [13]. Awalnya WebQual dibuat oleh Loiacono et al. (2002) Penggunaan WebQual banyak digunakan oleh banyak Page |34 orang untuk mengukur kualitas situs web, dan dapat mengidentifikasi 12 dimensi kualitas di situs web, dengan fokus utama pada evaluasi konsumen [14]. Namun, WebQual 4.0 hanya menggunakan lima dimensi: kepercayaan, kegunaan, informasi, desain, dan empati [15]. WebQual 4.0 dikembangkan sebagai cara untuk memberikan persepsi dalam pandangan pengguna atau pelanggan tentang kualitas yang disediakan oleh situs web e-commerce [16], sehingga dibutuhkan populasi yang akan diberikan sejumlah pertanyaan yang sesuai dengan metode WebQual 4.0, untuk mengetahui nilai yang akan dianalisis dan diolah oleh IPA di SPSS (Statistical Package for the Social Sciences).

Jumlah pengguna internet mempengaruhi sistem perdagangan atau transaksi jual dan beli yang saat ini dilakukan di dunia maya. Transaksi penjualan dan pembelian antara penjual dan pembeli melalui internet dikenal sebagai E-Commerce. Elevenia adalah salah satu E-Commerce terbaru di Indonesia, didirikan pada 1 Maret 2014. Model bisnis E-Commerce Elevenia adalah Customer-to-Customer (C2C). Sekarang ini, Customer-to-Customer (C2C) e-commerce telah berkembang pesat di seluruh dunia [17], [18]. Proses penjualan dari bisnis customer-to-customer $(C 2 C)$ ini memfasilitasi kegiatan yang terjadi antara pembeli dan penjual [17], [19]. Jenis C2C E-Commerce ini memudahkan pembeli untuk menemukan, memeriksa, dan membeli produk yang diinginkan [17], [18]. Selain itu juga membantu penjual untuk menjual lebih banyak produk mereka, terutama dalam mengurangi biaya yang harus dikeluarkan oleh perusahaan [17], [20]. Berdasarkan fakta dan perkembangan Elevenia yang hadir sebagai salah satu E-Commerce terbaru di Indonesia, penulis tertarik untuk meneliti kualitas situs E-Commerce Elevenia.

Perkembangan internet saat ini telah meningkat sangat pesat, terutama untuk perdagangan atau transaksi jual beli yang dilakukan secara online [21], [22]. Transaksi jual beli yang kami kenal sebagai $E$ Commerce telah mengalami pertumbuhan pesat di Indonesia. E-Commerce sangat populer di Indonesia dan ada begitu banyak investor yang bersaing untuk membangun E-Commerce di Indonesia untuk mendapatkan keuntungan dari kesempatan ini [21]. Hasil survei MasterCard menunjukkan pertumbuhan belanja online di Indonesia meningkat sebesar $15 \%$. Sebanyak $77 \%$ responden Indonesia menunjukkan kecenderungan berbelanja online. Elevenia adalah salah satu E-Commerce yang sebagian besar konsumennya adalah remaja hingga orang dewasa yang masih muda. Berdasarkan fakta-fakta ini, responden akan dipilih dari orang-orang yang berusia 15 hingga 30 tahun dan telah menggunakan situs web e-commerce Elevenia.

\section{METODE PENELITIAN}

\section{A. Proses dan Langkah Penelitian}

Setiap penelitian membutuhkan suatu proses penelitian yang menggambarkan bagaimana susunan penelitian berjalan dari awal sampai selesai, pentingnya keberadaan proses ini dilakukan agar aliran penelitian tetap pada jalur yang telah ditetapkan sehingga dapat meminimalkan kesalahan dan juga mempercepat dan membuat proses penelitian lebih efisien, berikut adalah tahap penelitian ini, lihat gambar 1, Langkah Penelitian.

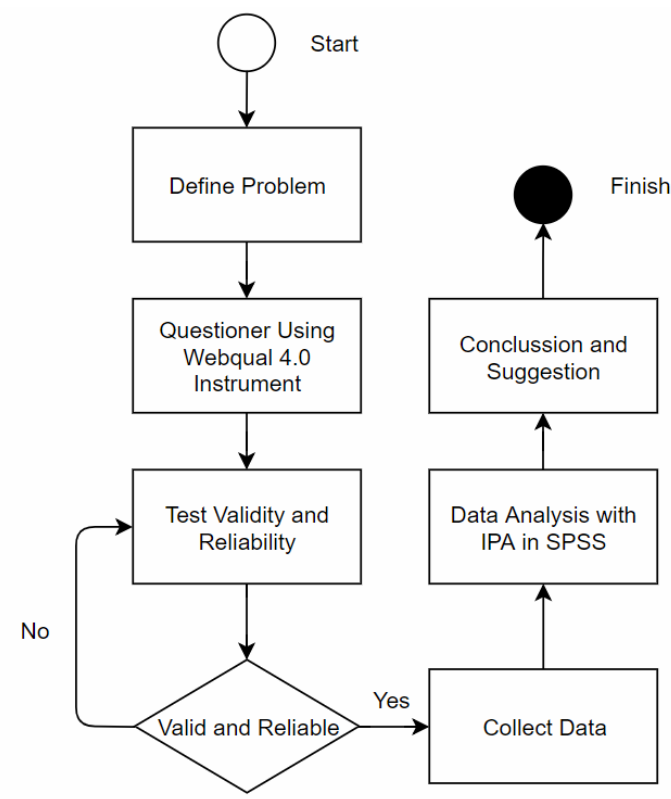

Gbr 1. Langkah Penelitian [23]

Pada gambar 1, Langkah Penelitian, dapat dilihat dengan jelas langkah-langkah penelitian ini, dimulai dari mendefinisikan masalah yang mana kita perlu mengetahui bagaimana pandangan pengguna tentang kualitas yang ditawarkan situs web Elevenia, maka selanjutnya kita akan membuat kuesioner menggunakan variabel WebQual 4.0 yang telah dibuktikan oleh Barnes dan Vitgen, maka data yang telah didapat akan diperiksa validitas dan reliabilitasnya, setelah data valid dan reliabel, data akan dikumpulkan dan dianalisis menggunakan IPA (Importance-Performance Analysis) dalam program SPSS (Statistical Package for the Social Sciences), dan kemudian dari data yang telah diproses dan diperoleh, kami akan membuat kesimpulan dan saran untuk situs web Elevenia.

\section{B. WebQual 4.0}

Penggunaan WebQual 4.0 adalah pilihan metode yang paling sesuai dengan tujuan dan masalah yang ada, yang dimana kami ingin tahu nilai kualitas situs Web Elevenia dari sudut pandang pengguna. WebQual 
4.0 dikompilasi berdasarkan penelitian pada tiga dimensi, yaitu: Usability, Information Quality, and Service Interaction, dan instrumen WebQual 4.0 memiliki 23 pertanyaan, dapat dilihat pada tabel 1 , Instrumen WebQual 4.0, yang akan diberikan kepada responden (Pengguna Dari Elevenia).

TABEL 1

INSTRUMEN WEBQUAL 4.0 [16]

\begin{tabular}{ll}
\hline Category & WebQual 4.0 questions \\
\hline Usability & UQ01. I find the site easy to learn to \\
& operate \\
UQ02. My interaction with the site is \\
clear and understandable \\
UQ03. I find the site to navigate \\
UQ04. I find the site easy to use \\
UQ05. The site has an attractive \\
appearance \\
UQ06. The design is appropriate to the \\
type of site \\
UQ07. The site conveys a sense of \\
competency \\
UQ08. The site creates a positive \\
experience for me \\
UQ09. Provides accurate information \\
\hline IQ10. Provides believable information \\
IQ11. Provides timely information \\
IQ12. Provides relevant information \\
IQ13. Provides easy to understand \\
information \\
IQ14. Provides information at the right \\
level of detail \\
IQ15. Present the information in an \\
appropriate format \\
SI16. Has a good reputation \\
SI17. It feels safe to complete \\
transactions \\
SI18. My personal information feels \\
Secure \\
SI19. Creates a sense of personalization \\
SI20. Conveys a sense of community \\
SI21. Makes it easy to communicate with \\
the organization \\
SI22. Ifeel confident that goods/ \\
services will be delivered as promised \\
SI23. Overall view of the Web site \\
&
\end{tabular}

\section{Importance Performance Analysis}

IPA menyediakan matriks yang dapat membantu membuat keputusan dan pengelompokan untuk mengilustrasikan atribut dari layanan yang menurut konsumen adalah yang paling penting [24]. IPA memungkinkan seorang manajer untuk membuat strategi operasi yang merupakan faktor penentu kesuksesan perusahaan [25]. IPA memiliki empat kuadran dibagi dengan sumbu $\mathrm{X}$ dan $\mathrm{Y}$, dan memiliki indikator untuk menentukan Performa dan Kepentingan, lihat gambar 2, Importance Performance Analysis.

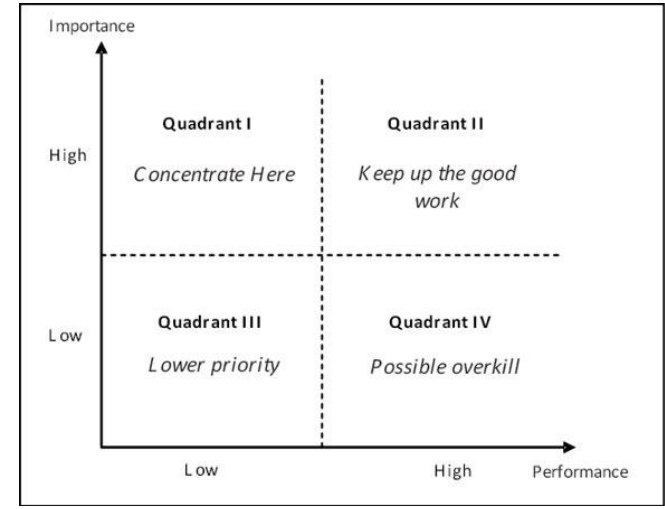

Gbr 2. Importance-Performance Analysis [26]

\section{Metode Kuantitatif Deskriptif}

Variabel pertanyaan yang digunakan dalam penelitian ini diambil dari metode WebQual 4.0 berdasarkan penelitian yang telah dibuktikan oleh Barnes dan Vitgen. Penelitian deskriptif ini dilakukan dengan tujuan membuat deskripsi yang sistematis, faktual dan akurat tentang fenomena yang diselidiki dan memiliki fakta, sifat, dan hubungan di antara mereka. [13]. Jumlah total responden yang mengisi kuesioner adalah 220 orang, tetapi hanya 50 orang telah menggunakan atau mencoba situs web $e$ commerce Elevenia, sehingga dalam analisis ini kami hanya menggunakan 50 data ini.

\section{E. Uji Validitas dan Reliabilitas}

Validitas dan Reliabilitas digunakan untuk menentukan tingkat kebenaran suatu proses survei atau penyediaan kuesioner yang telah diberikan kepada responden yang dipilih, ketika diketahui bahwa data yang telah diperoleh tidak valid, maka proses pengisian survei atau kuesioner harus diulang lagi untuk mendapatkan data yang valid [13].

\section{HASIL PEMBAHASAN}

\section{A. Uji Validitas}

Dalam studi ini, tes validitas menggunakan Pearson Correlation Product Moment dua arah. Data kuesioner diperoleh dari 50 responden yang merupakan pengguna Elevenia, diuji validitasnya dengan melakukan perbandingan antara $r$ hitung dan $r$ tabel dimana nilai $\mathrm{r}$ tabel diperoleh dari tabel product moment $\mathrm{r}$ dua arah dengan tingkat signifikansi $1 \%$ dengan $n=50$. Nilai $r$ tabel untuk $\mathrm{df}=48(\mathrm{df}=\mathrm{N}-2)$ adalah 0,3610. Jika $\mathrm{r}$ count $>\mathrm{r}$ tabel, maka item pertanyaan dari kuesioner adalah valid. Sebaliknya jika $r$ count $<r$ tabel maka item pertanyaan dari kuesioner tidak valid. Oleh karena itu, setiap item yang dipertanyakan harus memiliki nilai di atas 0,3610 agar valid. Lihatlah tabel 2, Variabel Validity WebQual 4.0, itu menunjukkan bahwa semua nilai hitung lebih besar dari $r$ tabel sehingga dapat disimpulkan bahwa semua item kuesioner adalah valid. 
TABEL 2.

VARIABEL VALIDITY WEBQUAL 4.0

\begin{tabular}{|c|c|c|c|c|c|}
\hline Attribute & $\begin{array}{c}\text { R Hitung } \\
\text { Actual }\end{array}$ & $\begin{array}{c}\text { Descriptio } \\
\text { n Actual }\end{array}$ & $\begin{array}{c}\text { R Hitung } \\
\text { Importance }\end{array}$ & $\begin{array}{c}\text { Description } \\
\text { Importance }\end{array}$ \\
\hline UQ01 & 0.649 & VALID & 0.747 & VALID \\
\cline { 2 - 6 } Page | 36 & 0.411 & VALID & 0.698 & VALID \\
\cline { 2 - 6 } & UQ03 & 0.615 & VALID & 0.622 & VALID \\
\cline { 2 - 6 } & UQ04 & 0.773 & VALID & 0.845 & VALID \\
\cline { 2 - 6 } & UQ05 & 0.539 & VALID & 0.722 & VALID \\
\cline { 2 - 6 } UQ06 & 0.520 & VALID & 0.768 & VALID \\
\hline UQ07 & 0.493 & VALID & 0.691 & VALID \\
\hline UQ08 & 0.653 & VALID & 0.723 & VALID \\
\hline UQ09 & 0.719 & VALID & 0.859 & VALID \\
\hline IQ10 & 0.645 & VALID & 0.800 & VALID \\
\hline IQ11 & 0.574 & VALID & 0.793 & VALID \\
\hline IQ12 & 0.740 & VALID & 0.753 & VALID \\
\hline IQ13 & 0.495 & VALID & 0.827 & VALID \\
\hline IQ14 & 0.493 & VALID & 0.705 & VALID \\
\hline IQ15 & 0.523 & VALID & 0.731 & VALID \\
\hline SI16 & 0.376 & VALID & 0.789 & VALID \\
\hline SI17 & 0.512 & VALID & 0.829 & VALID \\
\hline SI18 & 0.520 & VALID & 0.803 & VALID \\
\hline SI19 & 0.543 & VALID & 0.425 & VALID \\
\hline SI20 & 0.514 & VALID & 0.771 & VALID \\
\hline SI21 & 0.639 & VALID & 0.651 & VALID \\
\hline SI22 & 0.484 & VALID & 0.858 & VALID \\
\hline SI23 & 0.576 & VALID & 0.604 & VALID \\
\hline
\end{tabular}

\section{B. Uji Reliabilitas}

Dalam melakukan pengujian realibilitas pada penelitian ini, kami menggunakan koefisien Cronbach Alpha. Jika nilai Alpha Cronbach untuk seluruh variabel telah mendapati nilai melebihi 0,6 maka dapat disimpulkan bahwa variabel tersebut reliabel. Hasil pengujian reliabilitas dapat dilihat di tabel 3, Reliability Varia

TABEL 3.

RELIABILITY VARIABLE

\begin{tabular}{|c|c|c|c|c|}
\hline $\begin{array}{l}\text { Attri } \\
\text { bute }\end{array}$ & $\begin{array}{c}\text { Cronb } \\
\text { ach's } \\
\text { Alpha } \\
\text { Actual }\end{array}$ & $\begin{array}{c}\text { Description } \\
\text { Actual }\end{array}$ & $\begin{array}{c}\text { Cronbac } \\
\text { h's } \\
\text { Alpha } \\
\text { Importan } \\
\text { ce }\end{array}$ & $\begin{array}{c}\text { Description } \\
\text { Importance }\end{array}$ \\
\hline UQ & 0.818 & RELIABLE & 0.910 & RELIABLE \\
\hline IQ & 0.722 & RELIABLE & 0.878 & RELIABLE \\
\hline SI & 0.741 & RELIABLE & 0.883 & RELIABLE \\
\hline
\end{tabular}

\section{Perhitungan Performa dan Rata-rata Tingkat} Kepentingan

Pengukuran dari tingkat performa dan juga kepentingan menghitung jumlah total dan rata-rata dari semua jawaban responden pada atribut WebQual4.0, berdasarkan pengalaman penggunaan yang dirasakan oleh pengguna dari Elevenia, yang dapat dilihat di table 4, Hasil Kalkulasi. Dari hasil perhitungan dapat dilihat bahwa nilai yang diberikan pelanggan tentang performa dari Elevenia masih di bawah nilai yang diharapkan oleh pengguna. Berdasarkan dari tabel 4, Hasil Kalkulasi, perhitungan dari WebQual dapat dilakukan melalui perbandingan performa dan juga kepentingan yang harus dimiliki, dari perhitungan score gap dari masing masing atribut.

Dapat dilihat dari tabel 4, Hasil Kalkulasi, bila dianalisa, masih ada beberapa atribut yang masih memiliki score gap yang tinggi, atribut yang dapat dilihat memiliki score gap yang tinggi adalah, atribut yang memiliki nilai gap di atas rata-rata. Skor rata-rata diperoleh dari rata-rata selisih performance mean dan importance mean dari setiap atribut yang memiliki nilai rata-rata gap sebesar -.54. Dengan demikian Elevenia harus mengambil tindakan terhadap atribut yang memiliki nilai gap di atas rata-rata, karena hal tersebut menunjukan ketidakpuasan dari pelanggan, karena tingkat performa masih sangat jauh dari tingkat yang dianggap pelanggan tersebut adalah penting dan harus dicapai, hasil dari gap tersebut juga dapat digunakan oleh pihak Elevenia sebagai informasi untuk melakukan perbaikan pada variable-variabel tersebut.

Kalkulasi ini, nantinya akan digunakan untuk melakukan Importance Performance Analysis, dengan menggunakan bagian Peformance Mean dan juga bagian Importance Mean, tanpa menggunakan Average untuk kedua Importance Mean dan Performance Mean tersebut, yang nantinya data ini akan diolah dan disajikan kedalam diagram Cartesian yang digunakan untuk melakukan Importance Performance Analysis setelah ini.

TABEL. 4.

HASIL KALKULASI

\begin{tabular}{|c|c|c|c|c|c|}
\hline $\begin{array}{c}\text { Attrib } \\
\text { ute }\end{array}$ & $\begin{array}{c}\text { Perfor } \\
\text { mance } \\
\text { Score } \\
\text { Total }\end{array}$ & $\begin{array}{c}\text { Impor } \\
\text { tance } \\
\text { Score } \\
\text { Total }\end{array}$ & $\begin{array}{c}\text { Perfo } \\
\text { rman } \\
\text { ce } \\
\text { Mean }\end{array}$ & $\begin{array}{c}\text { Impor } \\
\text { tance } \\
\text { Mean }\end{array}$ & Gap \\
\hline UQ01 & 181 & 207 & 3.62 & 4.14 & -0.52 \\
\hline UQ02 & 174 & 201 & 3.48 & 4.02 & -0.54 \\
\hline UQ03 & 193 & 211 & 3.86 & 4.22 & -0.36 \\
\hline UQ04 & 183 & 213 & 3.66 & 4.26 & -0.60 \\
\hline UQ05 & 168 & 210 & 3.36 & 4.20 & -0.84 \\
\hline UQ06 & 174 & 193 & 3.48 & 3.86 & -0.38 \\
\hline UQ07 & 172 & 196 & 3.44 & 3.92 & -0.48 \\
\hline UQ08 & 177 & 211 & 3.54 & 4.22 & -0.68 \\
\hline UQ09 & 184 & 213 & 3.68 & 4.26 & -0.58 \\
\hline IQ10 & 185 & 218 & 3.70 & 4.36 & -0.66 \\
\hline IQ11 & 185 & 213 & 3.70 & 4.26 & -0.56 \\
\hline IQ12 & 191 & 202 & 3.82 & 4.04 & -0.22 \\
\hline IQ13 & 180 & 211 & 3.60 & 4.22 & -0.62 \\
\hline IQ14 & 166 & 196 & 3.32 & 3.92 & -0.60 \\
\hline IQ15 & 180 & 209 & 3.60 & 4.18 & -0.58 \\
\hline SI16 & 169 & 208 & 3.38 & 4.16 & -0.78 \\
\hline SI17 & 199 & 220 & 3.98 & 4.40 & -0.42 \\
\hline SI18 & 193 & 220 & 3.86 & 4.40 & -0.54 \\
\hline SI19 & 163 & 193 & 3.26 & 3.86 & -0.60 \\
\hline SI20 & 187 & 202 & 3.74 & 4.04 & -0.30 \\
\hline SI21 & 179 & 206 & 3.58 & 4.12 & -0.54 \\
\hline SI22 & 192 & 218 & 3.84 & 4.36 & -0.52 \\
\hline SI23 & 176 & 198 & 3.52 & 3.96 & -0.44 \\
\hline Avera & 180.48 & 207.3 & 3.61 & 4.15 & -0.54 \\
ge & & 5 & & & \\
\hline
\end{tabular}




\section{Hasil Importance Peformance Analysis}

Hasil nilai performa dan juga kepentingan dilanjutkan dengan memasukan analisis nilai tersebut kedalam diagram Cartesian menggunakan software SPSS atau Statistical Package for the Social Sciences.

Page | 37 Penggunaan metode Importance Performance Analysis digunakan untuk menunjukan peringkat dari nilai performa dan juga nilai kepentingan dari masingmasing atribut, untuk mengetahui atribut mana yang harus ditingkatkan maupun dipertahankan, dilihat dari nilai yang masuk ke empat kuadran dari diagram Cartesian pada gambar 3, Hasil Importance Performance Analysis.

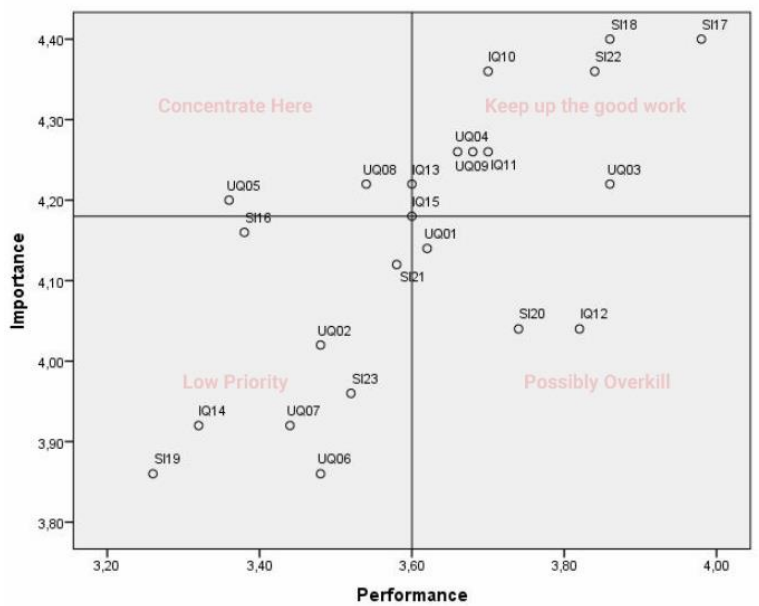

Gbr 3. Hasil Importance Performance Analysis

Pada Importance performance analysis, pemetaan data dibagi menjadi empat kuadran berdasarkan median, yang berada di dalam diagram Cartesian, dan berisi seluruh atribut yang memiliki pengaruh kepada kualitas situs web yang diuji. Hasil distribusi pada Importance Performance Analysis dapat dilihat pada figur 3, Hasil Importance Performance Analysis. Berikut adalah penjelasan dari masing-masing kuadran dalam Importance Performance Analysis yang menggunakan diagram Cartesian:

1) Kuadran Pertama (Concentrate Here)

Pada bagian ini, Elevenia harus menaruh perhatian khusus untuk meningkatkan performa website mereka, pada bagian ini menunjukan bagian yang memiliki tingkat performa yang cukup rendah, namun pengguna merasa bahwa tingkat kepentingan dari atribut ini sangatlah penting bagi mereka, sehingga dapat dilihat bahwa nilai UQ05 (Attractive Appearance) dan juga UQ08 (Positive Experience) berada pada bagian ini.

2) Kuadran Kedua (Keep Up The Good Work) Pada kuadran ini, Elevenia harus mempertahankan kualitas yang telah diberikan, bagian ini sudah cukup baik dalam performanya, di bandingkan dengan tingkat kepentinganya, sehingga nilai IQ13 (Provides Easy to Understand Information),
IQ15 (Present the Information in an Appropriate Format), UQ04 (The Site Easy to Use), UQ09 (Provides Accurate Information), IQ11 (Provides Timely Information), UQ03 (The Site Easy to Navigate), IQ10 (Provides Believeable Information), SI22 (Confident that Goods/Services will be Delivered as Promised), SI18 (Information Feels Secure), dan SI17 (Safe to Complete Transactions) berada pada bagian ini.

3) Kuadran Ketiga (Low Priority)

Pada kuadran ini, atribut memiliki tingkat kepentingan tidak terlalu tinggi, dan juga performa yang diberikan oleh website juga rendah, sehingga menjadi bagian yang tidak terlalu penting untuk user, namun ada baiknya, bahwa pada atribut ini, Elevenia juga memberikan perhatianya, walaupun tidak menjadi perhatian yang utama. Dapat dilihat pada bagian ini, bahwa UQ02 (Interaction with the Site is Clear and Understandable), UQ06 (Appropriate to the Type of Site), UQ07 (Conveys a Sense of Competency), IQ14 (Information at the Right Level of Detail), SI16 (Good Reputation), SI19 (Sense of Personalization), SI21 (Communicate with the Organization), dan SI23 (Overall View of the Web Site) berada pada bagian ini.

4) Kuadran Keempat (Possibly Overkill)

Pada kuadran ini, menunjukan bahwa performa yang diberikan Elevenia cukup tinggi, namun pengguna merasa bahwa hal tersebut bukan hal yang sangat utama atau penting, sehingga Elevenia dapat mengesampingkan terlebih dahulu beberapa atribut yang berada didalam kuadran ini, seperti UQ01 (Easy to Learn ro Operate), IQ12 (Provides Relevant Information), dan SI20 (Sense of Community) yang berada pada bagian ini.

\section{KESIMPULAN}

Berdasarkan hasil analisa dari kualitas website Elevenia berfokus pada tiga dimensi dari metode WebQual 4.0, dari sisi pandang user, rata-rata dari hasil kuesioner yang telah diberikan, merasa bahwa website Elevenia sudah memberikan rasa aman dan nyaman pada saat melakukan transaksi, namun harus ada beberapa aspek yang harus diperbaiki dan diperhatikan, seperti mayoritas user yang merasa bahwa tampilan dari website yang menurut mereka kurang atraktif, dan juga pengalaman berbelanja mereka yang sedikit tidak begitu baik. Hasil yang telah diberikan oleh Importance Performance Analysis, dapat digunakan sebagai feedback untuk memperbaiki kualitas website dimasa mendatang

\section{REFERENSI}

[1] Pauline Ratnasingam, "E-Commerce Relationships: The Impact Of Trust On Relationship Continuity," IJCM, vol. 15, no. 1, pp. 1-16, 2005.

[2] H. Darch and T. Lucas, "Training as an e-commerce enabler," J. Work. Learn., vol. 14, no. 4, pp. 148-155, 2002.

[3] G. Duffy and B. G. Dale, "E-commerce processes: A study of 
criticality," Ind. Manag. Data Syst., vol. 102, no. 8, pp. $432-$ $441,2002$.

[4] G. Sharma and W. Lijuan, "Ethical perspectives on ecommerce: An empirical investigation," Internet Res., vol. 24, no. 4, pp. 414-435, 2014.

[5] H. Ran, W. Zhuo, and X. Jianfeng, "Web quality of agile web development," Proc. - 2009 IITA Int. Conf. Serv. Sci. Manag.

Page | 38 Eng. SSME 2009, pp. 426-429, 2009.

[6] J. Chang, T. Song, C. Li, and T. Song, "Modeling Ecommerce website quality with quality function deployment," Proc. - IEEE Int. Conf. E-bus. Eng. ICEBE 2009; IEEE Int. Work. - AiR 2009; SOAIC 2009; SOKMBI 2009; ASOC 2009, pp. 417-422, 2009.

[7] Z. Liu, U. Northeast Normal, U. Heilongjiang, U. Liaoning Normal, U. Dalian Jiaotong, and T. Harbin Institute of, "Diagnosing E-commerce website quality based on DEA," 2nd Int. Conf. Comput. Sci. Netw. Technol. ICCSNT 2012, pp. 762-765, 2012.

[8] T. Zhou and S. Zhang, "Examining the effect of E-commerce website quality on user satisfaction," 2nd Int. Symp. Electron. Commer. Secur. ISECS 2009, vol. 1, pp. 418-421, 2009.

[9] J. B. Shao, Z. Wang, and X. X. Long, "The driving factor of customer retention: Empirical study on bank card," 2008 Int. Conf. Manag. Sci. Eng. 15th Аnnu. Conf. Proceedings, ICMSE, pp. 558-564, 2008.

[10] S. Coyles and T. C. Gokey, "Customer retention is not enough," 2006.

[11] K. A. Venetis and P. N. Ghauri, "Service quality and customer retention: building long-term relationships," Eur. $J$. Mark., vol. 38, no. 11/12, pp. 1577-1598, 2004

[12] M. Pegler, "Seven ways to hold fast to your customers," Handb. Bus. Strateg., vol. 5, no. 1, pp. 223-226, 2004.

[13] J. F. Andry, K. Christianto, and F. R. Wilujeng, "Using Webqual 4. 0 and Importance Performance Analysis To Evaluate Website Commerce," vol. 2555, 2018.

[14] A. Galati, M. Crescimanno, S. Tinervia, and D. Siggia, "Website quality and internal business factors: An empirical investigation in the Italian wine industry (2016) "Website quality and internal business factors: An empirical investigation in the Italian wine industry," Int. J. Wine Bus. Res., vol. 28, no. 4, pp. 308-326, 1108.

[15] E. Tamer H. and M. Abeer A., "Customer participation in online co-creation experience: the role of e-service quality," $J$. Res. Interact. Mark., vol. 9, no. 4, pp. 313-336, 2015.

[16] S. J. Barnes and R. Vidgen, "Measuring web site quality improvements: A case study of the forum on strategic management knowledge exchange," Ind. Manag. Data Syst., vol. 103, no. 5-6, pp. 297-309, 2003.

[17] K. Wei, Y. Li, Y. Zha, and J. Ma, "Trust, risk and transaction intention in consumer-to-consumer e-marketplaces," Ind. Manag. Data Syst., p. IMDS-10-2017-0489, 2018.

[18] C. Dan, "Consumer-To-Consumer (C2C) Electronic Commerce: The Recent Picture," Int. J. Networks Commun., vol. 4, no. 2, pp. 29-32, 2014.

[19] C. Avgerou and B. Li, "Relational and institutional embeddedness of Web-enabled entrepreneurial networks: Case studies of netrepreneurs in China," Inf. Syst. J., vol. 23, no. 4, pp. 329-350, 2013.

[20] M.-S. Kim and J. H. Ahn, "Comparison of trust sources of an online market-maker in the e-marketplace: Buyer's and seller's perspectives," J. Comput. Inf. Syst., vol. 47, no. 1, p. 84, 2006.

[21] D. Octavia and A. Tamerlane, "The Influence of Website Quality on Online Purchase Intentions on Agoda.Com with ETrust as a Mediator," Binus Bus. Rev., vol. 8, no. 1, p. 9, 2017.

[22] J. Salo and H. Karjaluoto, "A conceptual model of trust in the online environment," Online Inf. Rev., vol. 31, no. 5, pp. 604621, 2007.

[23] M. F. A. Budi Setiawan Santoso, "Analisis Kualitas Website Menggunakan Metode Webqual Dan Importance Performance Analysis (IPA) Pada Situs Kaskus," J-Ptiik, 2015.

[24] M. Y. Fraser McLeay, Andrew Robson, New applications for importance-performance analysis (IPA) in higher education : understanding student satisfaction. 2017.

[25] Karthiyayini Nagarajan, C. Rajendran, Munusamy Kumaravel, "Article information: Revised Version: ImportancePerformance Analysis ( IPA ) for Testing- and CalibrationLaboratories in India," 2016.

[26] G. H. Tzeng, H. F. Chang, and H. F. Chang, "Applying Importance-Performance Analysis as a Service Quality Measure in Food Service Industry," J. Technol. Manag. Innov., vol. 6, no. 3, pp. 106-115, 2011. 